\title{
A Empirical Study of the Determinants and Mechanism of Senior managers Compensation In Chinese Listed Private Companies
}

\author{
Yongdong Wang 1st \\ ShenYang Aerospace University \\ Econimics-Management School \\ ShenYang, China \\ wallyone@126.com
}

\author{
Liejin Lu 2nd \\ Liaoyang Vocational College of Technology \\ Culture-Economics School \\ Liaoyang, China \\ lvliejin@163.com
}

\begin{abstract}
This paper is an empirical study of the determinants and mechanism of senior managers' compensation. Previous studies found that senior managers' compensation was an effective means to reduce the company's agency costs between shareholders and executives. But they did not reach a consensus about the determinants. We discussed a special company group, which are Chinese listed private companies. We research the determinants of the managers' compensation, such as company scale and performance, governance mechanism, power of controlling shareholder. In addition, we research the medium role in these determinants. Then we draw the road path to test whether such a mechanism exists.
\end{abstract}

Keywords-senior managers; compensation; private companies; determinants; road path

\section{INTRODUCTION}

On the perspective of management knowledge, it is natural correlativity between senior managers' compensation and corporate performance. We can not imagine a losses company, while managers are highly paid. But the reality is so bizarre, which is frequent occurrence of such incidents in the market. When AIG Losses as high as $\$ 100$ billion, it Pay $\$ 16.5$ billion prize to senior managers with government aid money. In China, the compensation of Chairman and CEO of PingAn group company is 66 million RMB. He is the first high compensation man in Chinese A-share listed companies. In 2007, Erie Company implement equity incentive measures, it directly led the company to loss of 21 million RMB. We should think from these cases: what is the meaning of senior managers' compensation? What are the determinants of it? What is the mechanism of these determinants?

\section{LITERATURE REVIEW}

In Western academic, they did a lot of empirical researches on incentive problems of senior managers' compensation. Among the problem, the most concerned is correlativity between senior managers' compensation and corporate performance.

Jensen and Meckling (1976) found that the agency costs between managers and stockholder will cause managers pursuit of their own interests, while sacrifice stockholders' interests, such as loaf on the job, increase on-the-job consumption, or using free cash flow to pursuit of their own interests, not distributing cash dividend; even boycott merger and acquisition which is benefit to stockholder.

The senior managers' compensation is an effective means to reduce the company's agency costs. The empirical results of Murphy (1985) research show that it is positive correlation between senior managers' compensation and corporation performance. Morck,Shleifer,Vishny (1988) find that for USA samples it is adverse $U$ type relation between Managerial Ownership and corporate value. Jensen and Murphy (1990) research the correlation between three forms of compensation and corporation performance, find that CEO's compensation is weakly correlative to the performance. After their study, Hall and Lieberman used the same samples, adding the value change of stock and option, they measured the correlation of CEO's compensation and stockholder's wealth again, they found strongly correlative. The difference is caused by increasing options to senior managers from 1980.

In recent years, Media constantly reported CEO's high compensation, Caused social attend it. In fact, scholars have study the determinants of CEO's compensation many years. Murphy(1986),Gibbons and Murphy(1990) investigate the effective factors to senior managers' compensation, they found these effective factors such as: company scale, performance, managers' age, employment duration, whether is founder or external manager. Murphy(2001) point that original proposal of compensation is present by personnel department, then send to senior managers to modify, at last send to compensation committee to vote. In this process, senior managers can affect the design of himself compensation. Ramaswamy(2000) conclude these factors as three factors: human capital factor, corporate governance structure factors, the scale and performance.

In China, earlier studies found it was uncorrelated between performance and senior managers' compensation. In recent years, more and more researches found that the correlation is gradually rising, with the reform in corporation system and improving compensation. Private companies are special groups, the biggest characteristics is stock rights highly concentrated, family intervention in the process of company management. We think it must have some special 
determinants of senior managers' compensation, it worth to research.

\section{HYPOTHESIS}

Among these determinants, we do not consider the inherent characteristics of managers, such as capability, experience. We consider three factors: corporation governance structure, scale and performance. In this paper we consider a special factor, which is the power of dominant stockholder. According to study purpose, we make four hypothesis.

\section{$\mathrm{H}_{1}$ : Senior managers' compensation is correlative to} the company scale and performance

We think when the company scale is more or the performance is better, the managers' compensation is more. So we expected the correlation is positive. It needs different capability to manage a big scale company or a small one. The big company or better performance need more pay including time, energy, intelligence. Generally, the effort is proportionate to compensation, so compensation of big company managers is more than small others. The senior managers' compensation links up with performance or company scale, which is a basic approach.

$\mathrm{H}_{2}$ : Senior managers' compensation is correlative to corporation governance structure.

It needs to be verified that it is positive correlation or negative correlation. Generally, the more meeting times of board of directors, the big number of independent directors and board of supervisors is benefit to supervise managers. It is negative correlate to compensation. The increase numbers of board of directors and board of supervisors will cause to a case that compensation can be decide by themselves, so it is positive correlation. The managers increased may lead to compensation increased, it is positive correlation. The increasing proportion of stockholding to chairman and supervisory board chairman will increase restrain to managers, it is negative correlation. Certainly, the increasing holding stocks of senior managers will decrease their compensation, for a part of monetary compensation is tradeoff by holding stock.

$\mathrm{H}_{3}$;Senior managers' compensation is correlative to the power of dominant stockholder.

It needs to be verified that it is positive correlation or negative correlation. According to theory, Chinese private companies usually adopt Pyramid model to control other companies, which will cause the deviate between cash flow rights and voting rights. The dominant stockholder can control bottom companies in Pyramid, with less cash flow. The biggest disease of this kind of deviate is tunneling interest, it is harmful to subordinate companies performance. So compensation is negative correlation to the deviate.

$\mathrm{H}_{4}$; The scale and performance act mediating effect to compensation and governance structure, power of dominant stockholder.

The governance structure and power of dominant stockholder partly directly effects compensation, partly indirectly effects compensation though company scale and performance.

\section{SAMPLE AND DATA}

The data in this research is from database which named CCER private listed company. We use spss17.0 to analysis and test the data. The sample is from 2006 to 2010, there are 403 companies and 2015 records match to the research need. According to research need, we select 23 variables, the descriptive statistics results of these variables are in table- 1 .

Because some data can not be acquired, we define the compensation of senior managers as monetary compensation, did not consider the non-monetary compensation. The measured variables are L17 and L18, which are the sum of compensation of the first three highest amount directors, and the sum of compensation of the first three highest amount senior managers. The performance variables conclude income, net income, total assets, basic EPS. The senior manager includes CEO and other senior managers and members of the board of directors.

\begin{tabular}{|c|c|c|c|c|}
\hline var & $\min$ & $\max$ & mean & std \\
\hline$L 1$ & -95 & 14 & -14.48 & 37.392 \\
\hline$L 2$ & -95 & 35 & -9.73 & 39.748 \\
\hline$L 3$ & -95 & 30 & -34.57 & 47.265 \\
\hline$L 4$ & -95 & 16 & -13.24 & 37.902 \\
\hline$L 5$ & 0 & 19 & 5.56 & 1.601 \\
\hline$L 6$ & 0 & 10 & 3.28 & 0.902 \\
\hline$L 7$ & 0 & 9 & 1.71 & 1.918 \\
\hline$L 8$ & 0 & 13 & 3.88 & 1.863 \\
\hline$L 9$ & 0 & 11 & 3.54 & 1.094 \\
\hline$L 10$ & 0 & 0 & 0 & 0 \\
\hline$L 11$ & 0 & 7 & 0.63 & 1.004 \\
\hline$L 12$ & 0 & 8 & 2.59 & 1.214 \\
\hline$L 13$ & 0 & 3 & 0.07 & 0.142 \\
\hline$L 14$ & 0 & 0 & 0 & 0.014 \\
\hline$L 15$ & 0 & 1117058760 & 6044105.89 & $2.72 E+07$ \\
\hline$L 16$ & 0 & 3 & 0.03 & 0.103 \\
\hline$L 17$ & 0 & 15423100 & 665192.6 & 923462.342 \\
\hline$L 18$ & 0 & 43251700 & 644112.81 & 1051734.097 \\
\hline$L 19$ & 0.0001 & $7.55 E+10$ & $1.51 E+09$ & $3.67 E+09$ \\
\hline$L 20$ & $-2.81 E+09$ & $5.62 E+09$ & $1.01 E+08$ & $2.67 E+08$ \\
\hline$L 21$ & 0 & $4.83 E+10$ & $2.18 E+09$ & $3.41 E+09$ \\
\hline$L 22$ & 0 & 5.893 & 0.044 & 17.271 \\
\hline$L 23$ & $-6.50 E+01$ & 60.97 & 7.5959 & 8.967 \\
\hline
\end{tabular}

Note;

L1; The annual stockholders meeting times; L2;The annual 
board of directors meeting times

L3; The annual meetings of the board of directors In th e way of communication times

L4; The annual meeting of the board of supervisors times;L5;The size of the board of directors

L6; Total number of independent directors; L7;Total number of directors holding stocks

L8; Total number of directors getting pay;

L9; The size of the board of supervisors

L10; The number of independent supervisors;

L11; Total number of supervisors holding stock

L12; Total number of supervisors getting pay;

L13;Proportion of holding stock of chairman of the board

L14;Proportion of holding stock of supervisory board chairman;

L15; Quantity of holding stock of CEO

L16;Proportion of holding stock of CEO;

L17; The sum of compensation of the first three highest amount directors

L18; The sum of compensation of the first three highest amount senior managers ;

L19;Business income

L20;net income;

L21;total assets

;L22; basic EPS;

L23;deviate of power of dominant stockholder.

\section{THE EMPIRICAL RESULTS TEST AND ANALYSIS}

According to the hypothesis, we make multiple regression, with dependent variables of L18 and L17 respectively. The results are in table-2. As a whole, in model-1, regression equation $\mathrm{R} 2=0.32$, Model fitting is very good. In model-2, regression equation R2 $=0.16$, Model fitting is ordinary. Considering the determinants of senior managers' compensation is more complicated, model fitting is in the acceptable range.

Respectively, we can find from model-1 that among scale and performance factors, L20 and L21 is positive correlate to senior managers' compensation, which is in accord with null hypothesis $\left(\mathrm{H}_{1}\right)$. The others are not significant, and business income (L19) is reverse to null hypothesis $\left(\mathrm{H}_{1}\right)$. There are only five variables: L3, L6, L7, L8, L10, which are significant. Among these five variables, L3, L6, L10 are reverse to null hypothesis $\left(\mathrm{H}_{2}\right)$. The others are non-significant.

In model-1, governance structure factors are correlative to compensation, but L6 and L10 are is reverse to null hypothesis $\left(\mathrm{H}_{2}\right)$. Because independent director and independent supervisors are did not play its own part, instead captured by board of directors. The deviate of power of dominant stockholder is in accord with null hypothesis $\left(\mathrm{H}_{2}\right)$, and is significant.

In Model-2, L20 and L21 are in accord with null hypothesis $\left(\mathrm{H}_{1}\right)$, and is positive correlate to senior managers' compensation. Among governance structure factors, L3 is significant but is reverse to null hypothesis. The deviate of power of dominant stockholder is reverse to null hypothesis, and is not significant. In model-2, the determinants of senior managers' compensation are weakly affected by governance structure. Under the condition of removing human capital, there is only performance affected it, that is why $\mathrm{R}^{2}$ is very small, in Model-2.

\begin{tabular}{|c|c|c|c|c|c|c|c|}
\hline \multirow{2}{*}{ var } & \multirow{2}{*}{$\mathbf{H}$} & \multicolumn{3}{|c|}{ Model-1 (L17) } & \multicolumn{3}{|c|}{ Model-2(L18) } \\
\hline & & Beta & $\mathbf{t}$ & Sig. & Beta & $\mathbf{t}$ & Sig. \\
\hline $\mathbf{L 1}$ & - & -.147 & -.761 & .447 & -.109 & -.503 & .615 \\
\hline L2 & - & .051 & .359 & .720 & .151 & .942 & .346 \\
\hline L3 & - & .127 & 7.001 & $.000 *$ & .136 & 6.702 & $.000^{*}$ \\
\hline L4 & - & .344 & 1.812 & .070 & .160 & .752 & .452 \\
\hline L5 & - & -.021 & -1.006 & .315 & .011 & .457 & .648 \\
\hline L6 & - & .058 & 3.506 & $.000^{*}$ & .015 & .786 & .432 \\
\hline L7 & + & .045 & 2.170 & $.030 *$ & .036 & 1.564 & .118 \\
\hline L8 & + & .120 & 5.632 & $.000 *$ & .046 & 1.924 & .054 \\
\hline L9 & - & -.038 & -1.943 & .052 & -.031 & -1.424 & .154 \\
\hline 110 & - & .056 & 3.034 & $.002 *$ & .028 & 1.330 & .184 \\
\hline 111 & + & -.018 & -.845 & .398 & -.007 & -.307 & .759 \\
\hline 112 & + & -.013 & -.640 & .522 & -.022 & -.938 & .348 \\
\hline 114 & - & -.016 & -1.088 & .277 & -.017 & -1.053 & .292 \\
\hline 115 & - & -.008 & -.372 & .710 & .005 & .215 & .830 \\
\hline 116 & - & .019 & .750 & .454 & .013 & .461 & .645 \\
\hline L19 & + & -.001 & -.026 & .979 & -.024 & -.969 & .332 \\
\hline 120 & + & .179 & 8.390 & $.000 *$ & .143 & 5.966 & $.000^{*}$ \\
\hline 121 & + & .242 & 9.969 & $.000^{*}$ & .114 & 4.175 & $.000^{*}$ \\
\hline 122 & + & .006 & .409 & .682 & .006 & .382 & .702 \\
\hline L23 & - & -.031 & -2.192 & $.028 *$ & -.019 & -1.208 & .227 \\
\hline
\end{tabular}

Note;*express significant in 5\%level;+ express positive correlation;- express negative correlation; part of the variable is not suitable for model was eliminated

\section{ROAD PATH ANALYSIS}

In order to test null hypothesis $\mathrm{H}_{4}$, we need combine with above regress results. We use AMOS7.0 to draw a SEM road path (several variables do not fit mode are deleted). The results show in figure-1 and figure- 2 . In model- $\mathrm{P}_{1}$, we use two factors. $\mathrm{F}_{1}$ is express corporation governance factor; F2 is express the company scale and performance; L17 express the sum of compensation of the first three highest amount directors; L18 express the sum of compensation of the first three highest amount senior managers; L23 express deviate of power of dominant stockholder. Using SEM road path, we can find whether the mechanism between the determinants is effective.

The fit results of Model-P1 are RMSEA $=0.067>0.05$, $\mathrm{NFI}=0.950, \mathrm{RFI}=0.912, \mathrm{IFI}=0.953$, TLI $=0.917, \mathrm{CFI}=0.953$, 
above indicators are more than 0.90 , we can conclude Model-P $\mathrm{P}_{1}$ fit well.

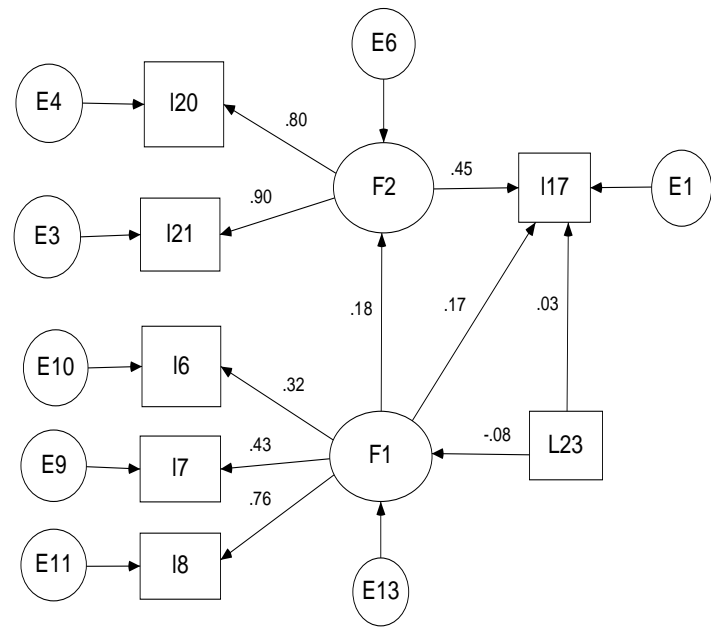

Figure-1;Model- $\mathrm{P}_{1}$

The fit results of Model- $\mathrm{P}_{2}$ are RMSEA $=0.075>0.0$ 5, NFI=0.987, RFI=0.960, IFI $=0.987$, TLI $=0.962, \mathrm{CFI}=0$. 987, above indicators are more than 0.90 . We can conc lude Model-P2 fit well.

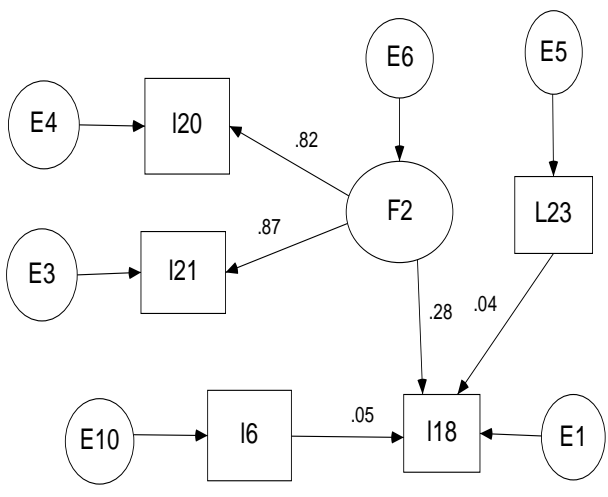

Figure-2;Model- $\mathrm{P}_{2}$

From Model- $\mathrm{P}_{1}$, measured variables are effective to $\mathrm{F} 2$, L20 to F2 is $0.80, \mathrm{~L} 21$ to F2 is 0.90 , both of them is more than 0.50. The correlation coefficient, F2 to L17, is 0.45 . This results show company scale and net income effectively form a factor, which influence director compensation.
Regretfully, the direct effective or partly mediating effect of governance factor and deviate of dominant stockholder power is not confirmed. For correlation coefficient, from F1 to F2 is only 0.18 , and correlation coefficient, from F1 to L17 is also only 0.17 , both of them is too small.

It is similar to Model- $\mathrm{P}_{2}$. The results show company scale and net income are effectively determinants to managers. But the direct influence or mediating effect is also not effective. Neither Model- $\mathrm{P}_{1}$, nor Model- $\mathrm{P}_{2}$ is in accord with null hypothesis $\left(\mathrm{H}_{4}\right)$

\section{EPILOGUE}

Summarizing the above results of this study, we can find, in Chinese private listed companies, among the determinants of senior managers' compensation, the scale and net income are most important. For the directors, holding stocks rights is another important factor. For the managers without holding stocks, the scale and net income is the only important factor. Certainly, in this study, an important defect is that we do not consider influences of managers' own human capital.

\section{REFERENCES}

[1] Ramaswamy, K. , Veliyath, R. , Gomes, L. A study of the determinants of CEO compensation in India [ J]. Management International Review, 2000,40:167-191.

[2] Jensen M C, K J Murphy. Performance Pay and top Management Incentives [ J] . Journal of Political Economy, 1990,98 (4):225-264.

[3] Hall B, K Lieberman. Are CEO's Really Paid like Bureaucrats? [J].Quarterly Journal of Economics,1998,113(8):653-691.

[4] Jensen, M. C. , W. Meckling. 1976. Theory o f the Firm: Managerial Behavior, Agency Costs and Ownerhip Structure.Journal of Financial Economics, 3 (4):305- 360.

[5] Murphy, K. J. 2001. Executive Compensation In: A shenfleter, O. , Card, D. , (Eds.). Handbook of Labor Economics, Vo .l 3. North-Holland, Amsterdam.

[6] Murphy, K. J. Corporate Performance and Managerial Remuneration: An Empirical Analysis [J]. Journal of Accounting and Economics,1985, 7(11-42)

[7] Gibbons, Robert, and Murphy, Kevin J. "Relative Performance Evaluation for Chief Executive Officers." Indus.and Labor Relations Rev. (1990), in press.

[8] Morck, R., A. Shleifer, and R. Vishny (1988), "Management ownership and market valuation," Journal of Financial Economics, 20, 293-315.

[9] R.Culpan V.Murti \& O.Culpan, Determinants of CEO Pay in Service Industry Firms, Group and Organization Management (formerly Group and Organization Studies), Vol. 17, No.2, 1992, pp.210-217. 